\title{
Improving genetic counseling access for parents of newborns who screen positive for cystic fibrosis: consensus guidelines
}

\author{
Elinor Langfelder-Schwind ${ }^{1}$, Karen Raraigh ${ }^{2}$, and Richard Parad ${ }^{3}$ \\ ${ }^{1}$ Icahn School of Medicine at Mount Sinai Department of Medicine \\ ${ }^{2}$ Johns Hopkins University \\ ${ }^{3}$ Brigham and Women's Hospital
}

November 2, 2021

\begin{abstract}
Introduction A risk associated with cystic fibrosis newborn screening (CFNBS) is parental misunderstanding of genetic information generated by the over 6,600 positive screens reported annually in the US. CFNBS algorithms incorporating DNA analysis can generate genetic information that requires clinical interpretation and has significance for the newborn, parents, and other relatives. Engagement between $\mathrm{CF}$ care centers and trained genetic counseling providers, such as licensed and/or certified genetic counselors (GCs), is variable and limited in providing information to CFNBS positive (CFNBS+) families. Methods Using a modified Delphi process, a workgroup of CF experts developed recommendations for engagement of genetic counseling services in CF care centers where CFNBS+ diagnostic evaluations are performed. Statements were assessed over three rounds of surveys, one face-to-face meeting, and through public feedback. Results Seventeen statements achieved $>80 \%$ consensus (range: 82-100\%). The workgroup affirmed prior CFF policy statements recommending genetic counseling for parents of infants with CFNBS+. The remaining statements addressed infrastructure and logistics of genetic counseling services, including defining appropriate training for genetic counseling providers and counseling content, establishing a path to equal access to genetic counseling providers across CF care centers, and setting a standard for client-centered CFNBS genetic counseling that is respectful of diverse patient needs and autonomy. Conclusions Implementation of client-centered genetic counseling for CFNBS+ families in $\mathrm{CF}$ care centers by providers with expertise in both $\mathrm{CF}$ and genetic counseling will require efforts to further define core concepts, enhance education of providers, and develop opportunities for access via telemedicine.
\end{abstract}

\section{Hosted file}

GC white paper_main_Submitted_280ct2021.docx available at https://authorea.com/users/444206/ articles/543995-improving-genetic-counseling-access-for-parents-of-newborns-who-screenpositive-for-cystic-fibrosis-consensus-guidelines

\section{Hosted file}

Table 1.docx available at https://authorea.com/users/444206/articles/543995-improvinggenetic-counseling-access-for-parents-of-newborns-who-screen-positive-for-cysticfibrosis-consensus-guidelines

\section{Hosted file}

Table 2.docx available at https://authorea.com/users/444206/articles/543995-improvinggenetic-counseling-access-for-parents-of-newborns-who-screen-positive-for-cysticfibrosis-consensus-guidelines

\section{Hosted file}


Table 3ab.docx available at https://authorea.com/users/444206/articles/543995-improvinggenetic-counseling-access-for-parents-of-newborns-who-screen-positive-for-cysticfibrosis-consensus-guidelines
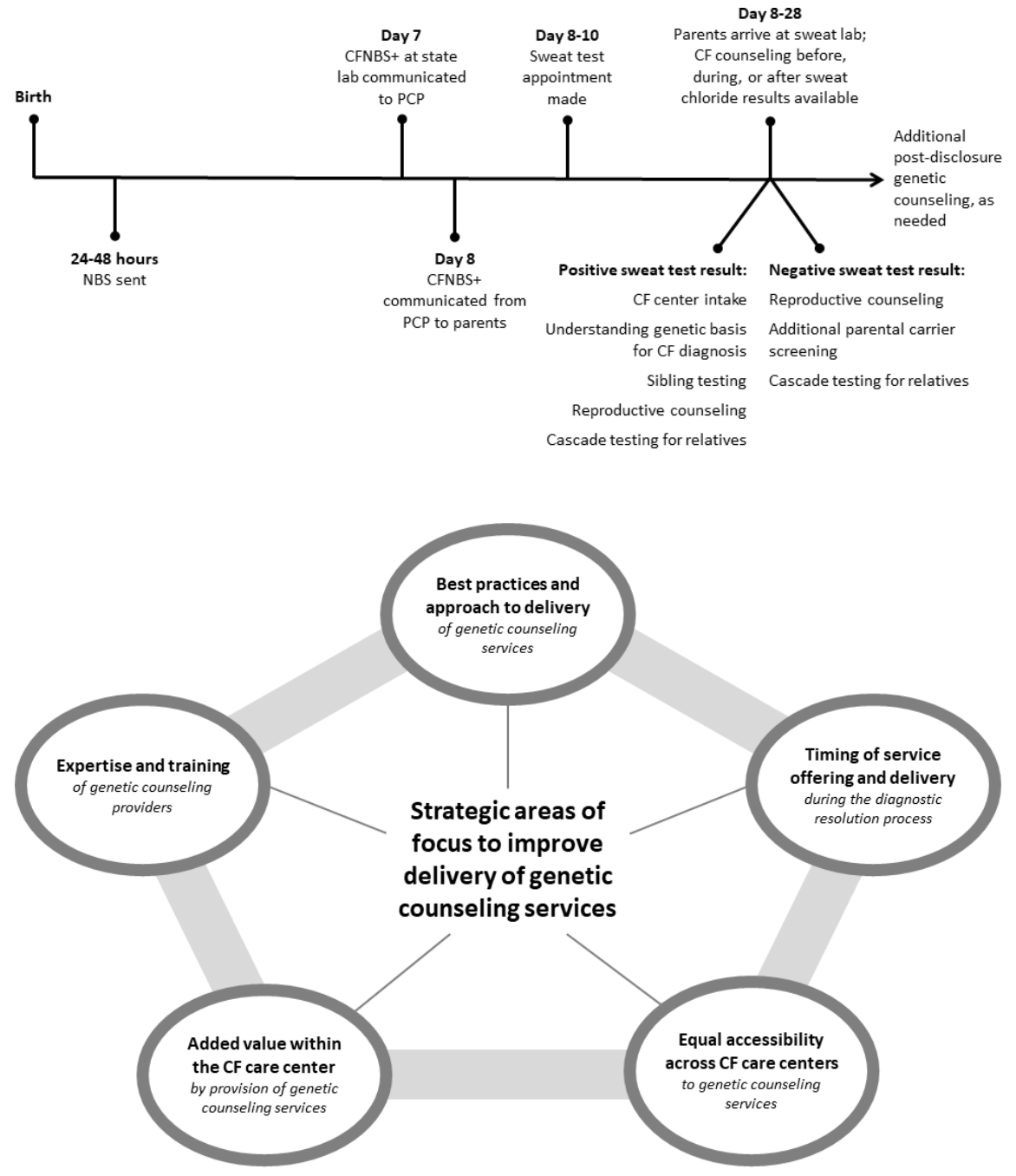